\title{
Real-World Data on Home End-Of-Life Care for Elderly Cancer Patients: A Yokohama Original Medical Database-Based Retrospective Analysis
}

Yukio Suzuki ( $\nabla$ yetii18@yahoo.co.jp )

Yokohama City University

Soshi Dohmae

City of Yokohama

Kohei Ohyama

City of Yokohama

Taiga Chiba

City of Yokohama

Sachiko Nakagami

City of Yokohama

Etsuko Miyagi

Yokohama City University

Jun Shuri

City of Yokohama

\section{Research Article}

Keywords: cancer, home medical care, home end-of-life care, super-aged society, administrative database

Posted Date: July 30th, 2021

DOI: https://doi.org/10.21203/rs.3.rs-744406/v1

License: (9) (i) This work is licensed under a Creative Commons Attribution 4.0 International License.

Read Full License 


\section{Abstract \\ Background}

Cancer incidence is expected to increase with population aging, making the availability of places for treating terminal cancer patients a pressing issue. Thus, home medical care is expected to play a crucial role. However, real-world big data on the actual state of home end-of-life care in Japan are limited. We aimed to clarify the real-world state of home end-of-life care for elderly cancer patients using data from an administrative database.

\section{Methods}

We analyzed the Yokohama Original Medical Database, which included 2,486,834 people and 29,411,895 medical invoices in 2014 and 2015. Data of target patients were extracted based on three criteria: age $\geq$ 65 years, malignant neoplasm diagnosis, and having a billing code of home end-of-life care. Medical fee points, including data related to home medical care, emergent admission, and survival time at home, were also analyzed.

\section{Results}

Overall, 1,323 people (554 and 769 aged $<80$ and $\geq 80$ years, respectively; males, $59.2 \%$ ) had planned to receive home end-of-life care. The $<80$-year group had more frequent emergent home visits than the $\geq 80$ year group $(p<0.001)$, but the number of monthly home visits was similar between the two groups $(p=$ $0.267)$. The average overall survival time at home was $3.9 \pm 4.4$ months, with the $<80$-year group having a shorter survival time than the $\geq 80$-year group $(p<0.001)$.

\section{Conclusions}

Terminal cancer patients aged $\geq 80$ years were less dependent on home medical care and had better prognosis at home than terminal cancer patients aged $<80$ years did. Our results can provide the basis for providing home medical care through a community-based integrated care system and for evidencebased policymaking.

\section{Background}

Japan is unprecedently moving toward being a super-aged society. By $2025,>30 \%$ of Japanese people will be older than 65 years and approximately $18 \%$ will be older than 75 years [1]. Moreover, by 2035, according to the estimation of the Cabinet Office in Japan, $>20 \%$ of Japanese people will be older than 75 years [1]. The same situation is predicted to occur in Yokohama City, which is the most populous city in Japan after 23 districts in Tokyo and has a population of 3.74 million. Yokohama City (area, $435 \mathrm{~km}^{2}$ ) 
is approximately 30 minutes away from central Tokyo by train and represents a corner of the Tokyo Metropolitan area. Updated vital statistics predict that the percentage of older individuals in Yokohama City will exceed $25 \%$ in 2025 and $30 \%$ in 2035 [2]. The proportions of patients aged $>65$ years who died from cancer (from 2014 to 2015) were $83.1 \%$ in Yokohama City [3] and 84.2\% nationally according to data from the National Cancer Center [2]. With the growth in the aging population, the proportion of elderly people expected to die from cancer is estimated to increase to $88.2 \%$ by 2025 [3]. Thus, it is important to focus on cancer care for the elderly.

Most cancer patients in Japan have so far spent the last moments of their lives in hospitals. However, due to the abovementioned factors, it is anticipated that there will be bed shortages for end-of-life care of terminal stage cancer patients, and meeting this increased demand for elderly cancer patients is a vital social concern. Therefore, a community-based integrated care system is being promoted as an important health care initiative in Japan. However, the actual status of clinical practice with respect to the number of planned home visits ( $\mathrm{p}-\mathrm{HVs}$ ), a home visit with a request from a patient (emergent home visits [e-HVs]), immediate home visits (i-HVs), and the detailed medical treatment has not yet been clearly defined. Moreover, real-world data on the overall survival after the transition to home medical care are limited. Although the government values home medical care and community-based integrated care systems for meeting the urgent needs in Japan, pain control becomes challenging when cancer patients are accepted into family clinics, and the doctors need to have extensive experience of palliative care. Thus, the number of doctors who accept cancer patients for end-of-life care is limited. To motivate family doctors to accept such patients, details of the burden of home medical care for cancer patients need to be provided. In contrast to Japanese situation, in Canada, which is known as a well-organized country in the implementation of palliative care, the location of death at home exceeds $60 \%$ in elderly people [4]. In addition, in many studies, the effectiveness of end-of-life care has been proven through population-based studies $[4,5]$. The community-based care is recommended to achieve better palliative care [6].

Awareness of the current situation of home end-of-life care (HEC) is indispensable to understand future supply and demand balance. Thus, we aimed to evaluate the current situation of HEC for elderly cancer patients in Yokohama City using an original administrative database to achieve further dissemination of HEC. Unlike existing medical databases such as registry records of specific diseases, this database was developed for policymaking at the local government level. It is expected to be the first step of evidencebased policymaking (EBPM) through the gathering of information on medical policy problems, which was recommended by The Center for Government Excellence at Johns Hopkins University [7].

\section{Methods}

\section{Database and setting}

Yokohama City is the most populous city in Japan and is governed by the local government for the Greater Tokyo Area, which includes Tokyo metropolis. Yokohama City has a population of approximately 3.75 million (January 2021), and the population distribution is as follows: individuals aged $<15$ years, 
$11.9 \%$; $15-64$ years, $62.8 \%$; and $\geq 65$ years, $25.2 \%$ (January 2021) [2]. The Yokohama Original Medical Database (YoMDB) [8] was built by Yokohama City after approval from the Information Disclosure and Personal Information Protection Review Board based on the Yokohama City Ordinance. This large medical invoice database can only be accessed by administrative officers from departments in charge of medical care and includes data on all residents of Yokohama City who have the following three government-funded insurance types: National Health Insurance, Long Life Medical Care System, and Public Assistance. The National Health Insurance is a system for farmers, self-employed people, and other such individuals. The Long Life Medical Care System is the system for all individuals aged $\geq 75$ years. The personal numbers of insurance and Public Assistance are hashed to protect the identity of individuals, and information that could reveal an individual's identity, such as their name and treatment details, is deleted to make the database secure.

This database includes $68.3 \%$ of Yokohama City residents aged $65-69$ years; $84.1 \%$ of residents aged $70-74$ years, with $99.7 \%$ of them aged $75-79$ years; and $98.6 \%$ of residents aged $>80$ years. Hence, it has a strong representation of the elderly and is an especially reliable database for those older than 75 years.

\section{Case selection}

The data from 2014 and 2015 included those of 2,486,834 people and 29,411,895 medical invoices. Target patients were selected based on three criteria: age $\geq 65$ years, death caused by a malignant neoplasm based on International Classification of Diseases (ICD)-10 codes (C00-C97), and additional HEC charges. The additional charge could have been applied by an insurance-participating medical facility when planned/emergent home medical care and nursing visits were provided more than twice for a total of 15 days (within 14 days before the day of death).

\section{Statistical analyses and definition of variables}

Patients' demographics, including age, sex, insurance type, cancer type, and institution type, were collected from the database. In this study, we divided the patients into the $<80$-year and $\geq 80$-year groups according to their age. The groups were compared according to each criterion for treatment planning in actual clinical practice. Cancer type was classified as follows: oral and oropharyngeal (International Classification of Diseases-10th revision [ICD-10] code C00-C14, C32), esophageal and gastric (C15, C16), colon (C18-C20), hepatobiliary and pancreatic (C22-C25), lung (C33-C34), skin (C43-C44), breast (C50), gynecologic (C53-C56), prostate (C61), urinary tract (C64-C68), brain (C70-C72), thyroid (C73), and blood (C81-C85, C88-C96) cancers.

HEC was classified based on the three types of home visits as follows: $\mathrm{p}-\mathrm{HV}, \mathrm{e}-\mathrm{HV}$, and i-HV. Furthermore, $\mathrm{i}-\mathrm{HV}$ s were divided according to the timing of the visit as follows: daytime $\mathrm{i}-\mathrm{HV}$ (visit during clinic hours), midnight i-HV (visit from 22:00 to 06:00), and night/holiday i-HV (visit at a time other than clinic hours and midnight). These classifications were consistent with the medical fee point system in Japan. 
Medical fee point data related to home medical care (coded as $\mathrm{C} 000$ to $\mathrm{C} 171-2$ ) were obtained based on the invoice of medical treatment for the target patients during the 2-year period and were analyzed. Admission was defined as the claim of the basic admission fee (coded as A100-109) or special admission fee (coded as A300-317), including admission to the critical care unit, intensive care unit, high care unit, palliative care unit, and community-based integrated care unit.

Emergent admission could not be directly confirmed due to the payment system. Cases with data on planned/emergent home medical care fee and hospitalization fee in the following month were referred to as cases of emergent hospitalization. Survival time at home was defined as the period from the first home medical care event to the month in which the additional fee for end-of-life care was charged.

Comparisons were made between the groups of patients aged $<80$ years and $\geq 80$ years. Statistical analyses were performed using Student's $t$-test (to compare the time of e-HV and i-HV and the number of home visits per month), $\chi^{2}$ test (to compare baseline characteristics, emergent admission, central venous nutrition, oxygen use, opioid use, $\mathrm{p}-\mathrm{HV}$ s by doctors or nurses three times a week or more, and death at home), and multiple regression (to compare survival time after HEC introduction). Sex, insurance type, and type of institution were added as covariates in the multiple regression analysis. $P$ values $<0.05$ were considered statistically significant. All statistical analyses were performed using Statistical Package for the Social Sciences, version 27 (International Business Machines Corporation, Armonk, NY, USA).

\section{Results}

\section{Baseline characteristics}

The complete data for 2014 and 2015 included those of 1,239,426 and 1,247,408 people and 14,467,489 and $14,944,496$ medical invoices, respectively. Our algorithm showed that 1,323 people had planned to receive HEC. The baseline characteristics of the patients are shown in Table 1. 
Table 1

Patient baseline characteristics

\begin{tabular}{|c|c|c|c|c|c|}
\hline & & All & $\begin{array}{l}<80 \\
\text { years }\end{array}$ & $\begin{array}{l}\geq 80 \\
\text { years }\end{array}$ & $P$ \\
\hline & & $\mathrm{n}(\%)$ & $\mathrm{n}(\%)$ & $\mathrm{n}(\%)$ & \\
\hline Number & & $\begin{array}{l}1,323 \\
(100)\end{array}$ & $\begin{array}{l}554 \\
(41.9)\end{array}$ & $\begin{array}{l}769 \\
(58.1)\end{array}$ & \\
\hline Sex & & & & & 0.001 \\
\hline & Male & $\begin{array}{l}783 \\
(59.2)\end{array}$ & $\begin{array}{l}358 \\
(64.6)\end{array}$ & $\begin{array}{l}425 \\
(55.3)\end{array}$ & \\
\hline & Female & $\begin{array}{l}540 \\
(40.8)\end{array}$ & $\begin{array}{l}196 \\
(35.4)\end{array}$ & $\begin{array}{l}344 \\
(44.7)\end{array}$ & \\
\hline Insurance types & & & & & $\begin{array}{l}< \\
0.001\end{array}$ \\
\hline & National Health Insurance & $\begin{array}{l}306 \\
(23.1)\end{array}$ & $\begin{array}{l}306 \\
(55.2)\end{array}$ & $0(0.0)$ & \\
\hline & Long Life Medical Care System & $\begin{array}{l}966 \\
(73.0)\end{array}$ & $\begin{array}{l}218 \\
(39.4)\end{array}$ & $\begin{array}{l}748 \\
(97.3)\end{array}$ & \\
\hline & Public Assistance & $51(3.9)$ & $30(5.4)$ & $21(3.7)$ & \\
\hline Cancer types & & & & & 0.383 \\
\hline & Lung & $\begin{array}{l}221 \\
(16.7)\end{array}$ & $\begin{array}{l}99 \\
(17.9)\end{array}$ & $\begin{array}{l}122 \\
(15.9)\end{array}$ & \\
\hline & Gastric & $\begin{array}{l}208 \\
(15.7)\end{array}$ & $\begin{array}{l}85 \\
(15.3)\end{array}$ & $\begin{array}{l}123 \\
(16.0)\end{array}$ & \\
\hline & Colon & $\begin{array}{l}177 \\
(13.4)\end{array}$ & $\begin{array}{l}72 \\
(13.0)\end{array}$ & $\begin{array}{l}105 \\
(13.7)\end{array}$ & \\
\hline & Pancreatic & $103(7.8)$ & $47(8.5)$ & $56(7.3)$ & \\
\hline & Liver & $85(6.4)$ & $30(5.4)$ & $55(7.2)$ & \\
\hline & Prostate & $71(5.4)$ & $30(5.4)$ & $41(5.3)$ & \\
\hline & Urinary tract & $62(4.7)$ & $22(4.0)$ & $40(5.2)$ & \\
\hline & Biliary tract & $60(4.5)$ & $19(3.4)$ & $41(5.3)$ & \\
\hline & Blood & $44(3.3)$ & $14(2.5)$ & $30(3.9)$ & \\
\hline & Esophageal & $43(3.3)$ & $21(3.8)$ & $22(2.9)$ & \\
\hline & Gynecologic & $35(2.6)$ & $19(3.4)$ & $16(2.1)$ & \\
\hline & Breast & $34(2.6)$ & $17(3.1)$ & $17(2.2)$ & \\
\hline
\end{tabular}




\begin{tabular}{|c|c|c|c|c|c|}
\hline & & All & $\begin{array}{l}<80 \\
\text { years }\end{array}$ & $\begin{array}{l}\geq 80 \\
\text { years }\end{array}$ & $\mathbf{P}$ \\
\hline & & $\mathrm{n}(\%)$ & n (\%) & $\mathrm{n}(\%)$ & \\
\hline & $\begin{array}{l}\text { Others (including metastatic } \\
\text { cancer) }\end{array}$ & $\begin{array}{l}180 \\
(13.6)\end{array}$ & $\begin{array}{l}79 \\
(14.3)\end{array}$ & $\begin{array}{l}101 \\
(13.1)\end{array}$ & \\
\hline Institution & & & & & 0.89 \\
\hline & Clinic & $\begin{array}{l}1250 \\
(94.5)\end{array}$ & $\begin{array}{l}524 \\
(94.6)\end{array}$ & $\begin{array}{l}726 \\
(94.4)\end{array}$ & \\
\hline & Hospital & $73(5.5)$ & $30(5.4)$ & $43(5.6)$ & \\
\hline $\begin{array}{l}\text { Location of } \\
\text { institution }\end{array}$ & & & & & $\begin{array}{l}< \\
0.001\end{array}$ \\
\hline & In Yokohama City & $\begin{array}{l}1200 \\
(90.7)\end{array}$ & $\begin{array}{l}518 \\
(93.5)\end{array}$ & $\begin{array}{l}682 \\
(88.7)\end{array}$ & \\
\hline & Outside of Yokohama City & $123(9.3)$ & $36(6.5)$ & $87(11.3)$ & \\
\hline
\end{tabular}

The proportions of male and female patients were $59.2 \%$ and $40.8 \%$, respectively. The numbers of medical invoices for planned and on-call home visits (per 1,000 people) in 2014 and 2015 obtained from the YoMDB were as follows: 554 for residents aged $<80$ years and 769 for residents aged $\geq 80$ years. The proportion of men was higher in the $<80$-year group than in the $\geq 80$-year group $(p=0.001)$. Insurance types were as follows: 306 (23.1\%), 966 (73.0\%), and 51 (3.9\%) patients received National Health Insurance, Medical Care System for Older Senior Treatment, and Public Assistance, respectively. The types of cancers were as follows: 221 (16.7\%), 208 (15.7\%), 177 (13.4\%), 103 (7.8\%), 85 (6.4\%), and 71 (5.4\%) patients had lung, gastric, colon, pancreatic, liver, and prostate cancer, respectively (Table 1). Clinics were largely responsible for patients receiving HEC (94.5\%).

\section{Results of home end-of-life care (HEC)}

The clinical performance and outcome index of HEC are shown in Table 2. The average number of overall e-HVs was 1.3 times per person-month. 
Table 2

Clinical performance and outcome index regarding HEC

\section{The clinical performance and outcome index regarding HEC}

\begin{tabular}{|c|c|c|c|c|}
\hline & All & $\begin{array}{l}<80 \\
\text { years }\end{array}$ & $\begin{array}{l}\geq 80 \\
\text { years }\end{array}$ & $P$ \\
\hline & $\begin{array}{l}(\mathrm{n}= \\
1,323)\end{array}$ & $(n=554)$ & $(n=769)$ & \\
\hline $\begin{array}{l}\text { Overall e-HV } \\
\text { (times/person-month, average } \pm \text { SD) }\end{array}$ & $1.3 \pm 1.1$ & $1.5 \pm 1.1$ & $1.2 \pm 1.1$ & $<.001$ \\
\hline $\begin{array}{l}\text { Overall i-HV } \\
\text { (times/person-month, average + SD) }\end{array}$ & $0.5 \pm 0.7$ & $0.6 \pm 0.7$ & $0.5 \pm 0.6$ & 0.001 \\
\hline $\begin{array}{l}\text { Daytime i-HV } \\
\text { (times/person-month, average + SD) }\end{array}$ & $0.1 \pm 0.4$ & $0.2 \pm 0.4$ & $0.1 \pm 0.3$ & 0.056 \\
\hline $\begin{array}{l}\text { Night/holiday i-HV (times/person-month, average + } \\
\text { SD) }\end{array}$ & $0.2 \pm 0.4$ & $0.2 \pm 0.5$ & $0.2 \pm 0.4$ & 0.092 \\
\hline $\begin{array}{l}\text { Midnight i-HV } \\
\text { (times/person-month, average + SD) }\end{array}$ & $0.2 \pm 0.4$ & $0.2 \pm 0.4$ & $0.2 \pm 0.4$ & 0.011 \\
\hline Emergent admission, $\mathrm{n}(\%)$ & $62(4.7)$ & $17(3.1)$ & $45(5.9)$ & 0.018 \\
\hline Central venous nutrition, $\mathrm{n}(\%)$ & $90(6.8)$ & $48(8.7)$ & $42(5.5)$ & 0.022 \\
\hline Oxygen use at home, $\mathrm{n}(\%)$ & $\begin{array}{l}500 \\
(37.8)\end{array}$ & $\begin{array}{l}218 \\
(39.4)\end{array}$ & $\begin{array}{l}282 \\
(36.7)\end{array}$ & 0.321 \\
\hline Opioid use, n (\%) & $\begin{array}{l}1014 \\
(76.6)\end{array}$ & $\begin{array}{l}476 \\
(85.9)\end{array}$ & $\begin{array}{l}538 \\
(70.0)\end{array}$ & $<.001$ \\
\hline $\begin{array}{l}\text { Three or more } \mathrm{p}-\mathrm{HV} \text { s by a doctor or nurse in a week, } \mathrm{n} \\
(\%)\end{array}$ & $\begin{array}{l}132 \\
(10.0)\end{array}$ & $56(10.1)$ & $76(9.9)$ & 0.893 \\
\hline Death at home, n (\%) & $\begin{array}{l}1261 \\
(95.3)\end{array}$ & $\begin{array}{l}532 \\
(96.0)\end{array}$ & $\begin{array}{l}729 \\
(94.8)\end{array}$ & 0.296 \\
\hline
\end{tabular}

HEC, home end-of-life care; p-HV, planned home visit; e-HV, emergent home visit; i-HV, immediate home visit.

Daytime is defined as clinic hours. Midnight is defined as the time from 22 p.m. to 6 a.m. Night/holiday is defined as the time other than clinic hours and midnight.

The $<80$-year group received more e-HVs than the $\geq 80$-year group (1.5 vs. 1.2 times/person-month, $\mathrm{p}<$ $0.001)$, especially outside the outpatient clinic $(p=0.001)$. The rate of emergent admission was $5.9 \%$ in the $\geq 80$-year group, which was higher than that in the $<80$-year group $(3.1 \% ; p=0.018)$. Conversely, the 
rates of central venous nutrition and opioid use were higher in the $<80$-year group than those in the $\geq 80$ year group. The need for more than 3 days of $\mathrm{HVs}$ and/or nursing visits per week, the rate of death in the patient's home, and oxygen use were not significantly different between the two groups.

The maximum numbers of $\mathrm{p}-\mathrm{HV}$ s and e-HVs per month within 6 months from death are shown in Fig. 1. The average number of home visits for all patients was $5.1 \pm 2.6$. There was no difference in the number of home visits per month between the two groups (5.1 vs. 5.0, $p=0.267$ ).

\section{Survival time after HEC introduction}

The survival time after HEC introduction is shown in Fig. 2. The average overall survival time at home was $3.9 \pm 4.4$ months. The average survival time at home was longer in the $\geq 80$-year group than that in the < 80-year group (4.6 vs. 2.9 months, $p<0.001$ ). Moreover, in the multiple regression analysis adjusted for sex and the location of the home care clinic (in Yokohama or a neighboring city), the average survival time at home was significantly longer in the $\geq 80$-year group than in the $<80$-year group $\left(\beta=0.17, R^{2}=\right.$ $0.54, p<0.001)$.

\section{Discussion}

To promote the concept of EBPM, we analyzed an original and large local government-based medical database consisting of medical invoice data. We found that patients received HEC regardless of their cancer type and that their average overall survival time at home was 3.9 months, which was longer than we expected. Furthermore, through our analysis, the necessary home medical care resources and monthly frequency of HVs were identified. This comprehensive database analysis with a high coverage of individuals aged $\geq 65$ years showed that terminal cancer patients older than 80 years were less dependent on home medical care and had a better prognosis at home. To the best of our knowledge, this is the first such analysis performed using a large, local government-based medical administrative database in Japan.

One of the significant contributions of this study was that it provided high-value real-world data on survival time after HEC introduction, which is difficult to analyze through medical invoice data in the Japanese system wherein survival time cannot be directly obtained. The YoMDB is strongly representative of the elderly population because the insurance system in Japan focuses on this population [8]. Moreover, the YoMDB is a highly comprehensive database for those older than 65 years. This universality is useful for EBPM. We targeted patients aged $\geq 65$ years in this study because the proportion of patients aged $\geq 65$ years who died of cancer was $>83 \%$ [3]. Therefore, such a focused analysis was important from the viewpoint of advancing medical care in the near future for an aging society.

In the Japan HOspice and Palliative care Evaluation study, which was the first large nationwide study focusing on end-of-life care that surveyed bereaved families, home hospice care was found to be superior to end-of-life care at a cancer center in terms of the overall care satisfaction of the bereaved family, care 
evaluation scale scores [9], and good death inventory scores [10]. In another cohort study, cancer patients receiving HEC were found to have a better prognosis than those receiving hospital care [11].

Elderly patients with advanced disease, especially cancer patients, preferred HEC (odds ratio, 3.72) [12]. There is a trend for an increase in the number of cancer patients aged $\geq 65$ years who want to die in their homes [12]. This finding is similar to that obtained in a previous Japanese study, which demonstrated that $72.8 \%$ of Japanese individuals would like to spend the end of their lives at home if they are diagnosed with cancer [13]; approximately $80 \%$ of those in their 70 s desired to spend their last moments at home [13]. However, $41.6 \%$ of respondents thought that this would be difficult to accomplish [13], which highlights the problems of social support and medical resource shortage.

In our study, the elderly could spend more time at home than expected. A retrospective study of home palliative care in 450 patients with advanced cancer in Japan showed poorer prognosis than that reported in our study [14]. We believe that this difference arises from the differences in the nature of the hospital-based medical record database. On the contrary, our administrative database had high coverage because it contained real-world data.

The YoMDB is a useful administrative database for analyzing real-world data as it contains data of local residents in Yokohama City. Health care policymaking is essential for ensuring a healthy society; thus, evidence-based policies, similar to those used to treat a patient in a hospital or clinic, should be developed. There is an urgent need to develop human resources responsible for home medical care and a medical care provision system that can meet the increasing demand for HEC for elderly cancer patients in the near future. A local government and local medical association that manage a community-based integrated care system should proceed to increase the number of home care clinics involving cancer terminal care. An effective question to clinics might be as follows: "How would you like to start HEC for cancer patients from $\geq 80$-year patients?"

This study has several limitations. First, given the nature of the receipt database (it is based on a fixed code for the practice performed), we could not confirm the practice or outcome that we would like to have directly obtained. This may have resulted in some information bias. Second, because the reason for emergency hospitalization could not be correctly determined, it was difficult to analyze in detail whether palliation was acute, whether it was for respite purposes, or whether there was a different underlying requirement. Third, the analyses of medical invoice databases are limited because Japanese receipt data are originally used for the calculation of medical treatment fee, and analysis of the patient's condition and severity of underlying disease or comorbidity using these data was not possible.

\section{Conclusions}

This study reported that terminal cancer patients aged $\geq 80$ years were less dependent on home medical care and had better prognosis at home than patients aged $<80$ years. In areas where the population will continue to age further, such as Japan, the need for HEC for cancer patients will definitely increase, and the development of social resources to meet this demand is an urgent social issue. Our results are 
valuable as they can be used as the basis for providing HEC through a community-based integrated care system and will be useful for raising awareness and for human resource development. In particular, for medical institutions that intend to start HEC for cancer patients, starting from patients aged $\geq 80$ years could be a useful and concrete first step as these patients have a relatively low degree of medical dependence.

\section{List Of Abbreviations}

p-HV Planned home visit

e-HV Emergent home visit

i-HV Immediate home visit

HEC Home end-of-life care

EBPM Evidence-based policymaking

YoMDB Yokohama Original Medical Database

\section{Declarations}

The authors report no potential conflicts of interests.

\section{Ethical approval and consent to participate}

This study protocol was approved by the Institutional Ethics Committee of Yokohama City University School of Medicine (B180700010). This study used an opt-out system at the official HP of Yokohama City instead of obtaining informed consent. This study was conducted in compliance with the provisions of the Declaration of Helsinki (as revised in Brazil 2013).

\section{Consent for publication}

Not applicable

\section{Availability of data materials}

The datasets generated and analyzed during the current study are available only for officers in Medical Policy Division, Medical Care Bureau.

\section{Competing interests}

The authors declare that they have no competing interests.

\section{Funding}


Not applicable.

\section{Authors' contributions}

All authors have made substantial contributions to the study and manuscript preparation. YS was responsible for the study design, data collection, analysis, and interpretation. SD was also responsible for data collection and analysis. KO, EM, and JS assisted in the data interpretation. All authors have read and approved the final manuscript.

\section{Acknowledgments}

The authors would like to thank the members of the Medical Care Bureau, City of Yokohama, for their cooperation with this study. We would like to thank Editage (www.editage.jp) for English language editing.

\section{Author's information}

${ }^{1}$ Department of Obstetrics and Gynecology, Yokohama City University Graduate School of Medicine, Yokohama, Japan

${ }^{2}$ Medical Policy Division, Medical Care Bureau, Yokohama, Japan

\section{References}

1. Annual Report on the Aging Society: 2015. Cabinet Office, Japan. 2020. https://www8.cao.go.jp/kourei/english/annualreport/index-wh.html. Accessed 1 March 2021.

2. Yokohama City Future Population Estimate. Policy Bureau, City of Yokohama. 2020. http://www.city.yokohama.lg.jp/seisaku/seisaku/jinkosuikei/. Assessed 1 March 2021.

3. Cancer Registry and Statistics. Cancer Information Service, National Cancer Center, Japan. 2020. https://ganjoho.jp/reg_stat/statistics/dl/index.html. Accessed 1 March 2021.

4. Quinn KL, Wegier P, Stukel TA, Huang A, Bell CM, Tanuseputro P. Comparison of palliative care delivery in the last year of life between adults with terminal non cancer illness or cancer. JAMA Netw Open. 2021;4:e210677.

5. De Palma R, Fortuna D, Hegarty SE, Louis DZ, Melotti RM, Moro ML. Effectiveness of palliative care services: a population-based study of end-of-life care for cancer patients. Palliat Med. 2018;32:1344-52.

6. Mitchell G, Aubin M, Senior H, Johnson C, Fallon-Ferguson J, Williams B, et al. General practice nurses and physicians and end of life: a systematic review of models of care. BMJ Support Palliat Care. 2020;bmjspcare-2019-002114.

7. Klosek K. A road map for policy change. In: The Center for Government Excellence at Johns Hopkins University. GovEx. 2018. https://govex.jhu.edu/wiki/a-roadmap-for-policy-change/. Accessed 1 
March 2021.

8. Suzuki Y, Dohmae S, Ohyama K, Nishino H, Fujii H, Shuri J. Demand for home medical care will continue to increase in the next decades: an analysis from the Yokohama Original Medical Database (YoMDB). Geriatr Gerontol Int. 2018;18:1578-9.

9. Morita T, Hirai K, Sakaguchi Y, Maeyama E, Tsuneto S, Shima Y, et al. Measuring the quality of structure and process in end-of-life care from the bereaved family perspective. J Pain Symptom Manage. 2004;27:492-501.

10. Miyashita M, Morita T, Sato K, Hirai K, Shima Y, Uchitomi Y. Good death inventory: a measure for evaluating good death from the bereaved family member's perspective. J Pain Symptom Manage. 2008;35:486-98.

11. Hamano J, Yamaguchi T, Maeda I, Suga A, Hisanaga T, Ishihara T, et al. Multicenter cohort study on the survival time of cancer patients dying at home or in a hospital: does place matter? Cancer. 2016;122:1453-60.

12. Higginson IJ, Daveson BA, Morrison RS, Yi D, Meier D, Smith M, et al. Social and clinical determinants of preferences and their achievement at the end of life: prospective cohort study of older adults receiving palliative care in three countries. BMC Geriatr. 2017;17:271.

13. Consciousness Survey about Hospice, Palliative Care 2018. Japan Hospice Palliative Care Foundation, Osaka. 2018. https://www.hospat.org/assets/templates/hospat/pdf/ishikichousa2018.pdf. Accessed 1 March 2021.

14. Otsuka M. Factors associated with length of stay at home in the final month of life among advanced cancer patients: a retrospective chart review. J Palliat Med. 2017;20:884-9.

\section{Figures}




\section{5}

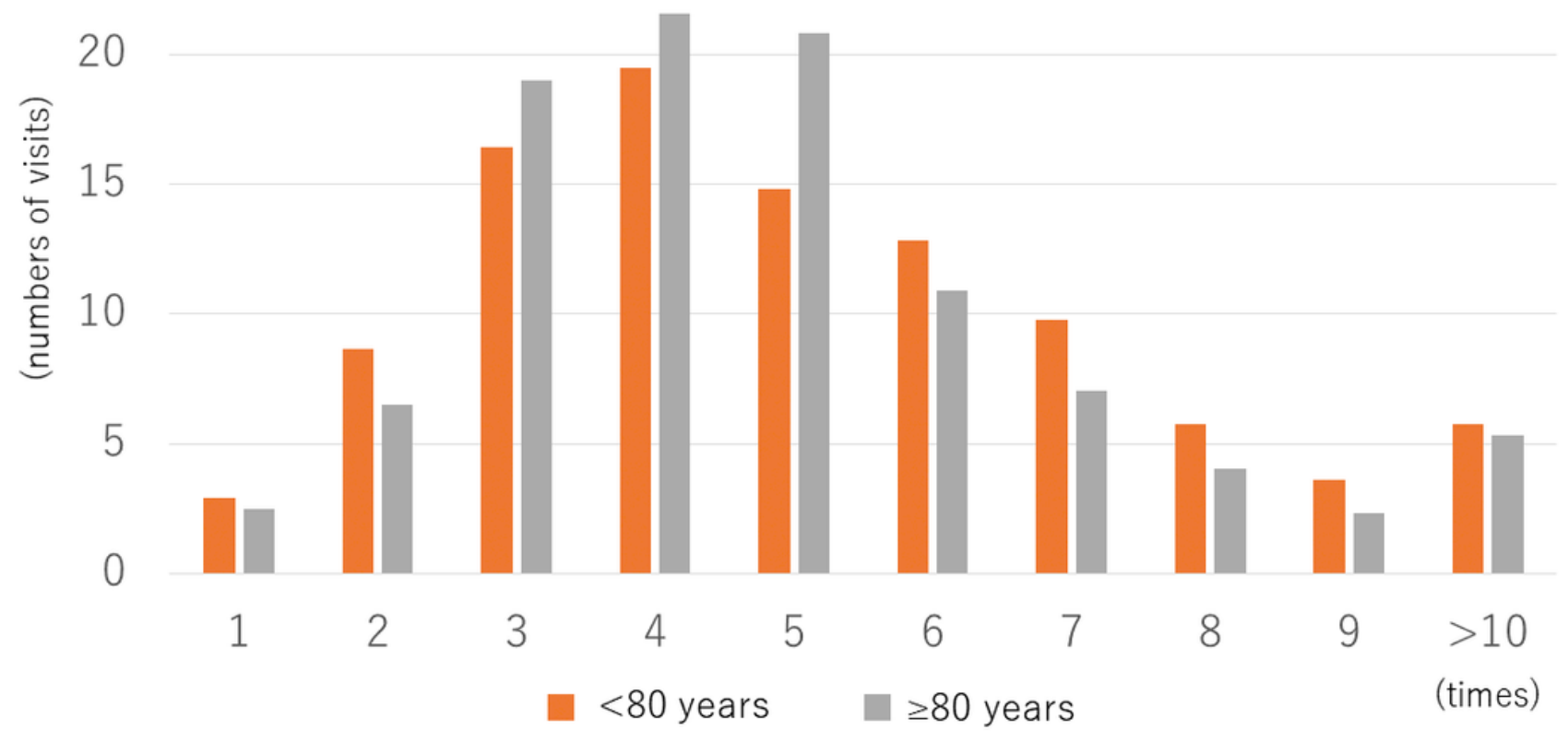

\section{Figure 1}

Maximum number of $\mathrm{p}-\mathrm{HVs}$ and e-HVs per month within 6 months of death. The average number of home visits among all patients was $5.1 \pm 2.6$. There was no difference in the number of home visits per month between the <80-year and $\geq 80$-year groups (5.1 vs. $5.0, p=0.267$ ). p-HVs, planned home visits; eHVs, emergent home visits. 


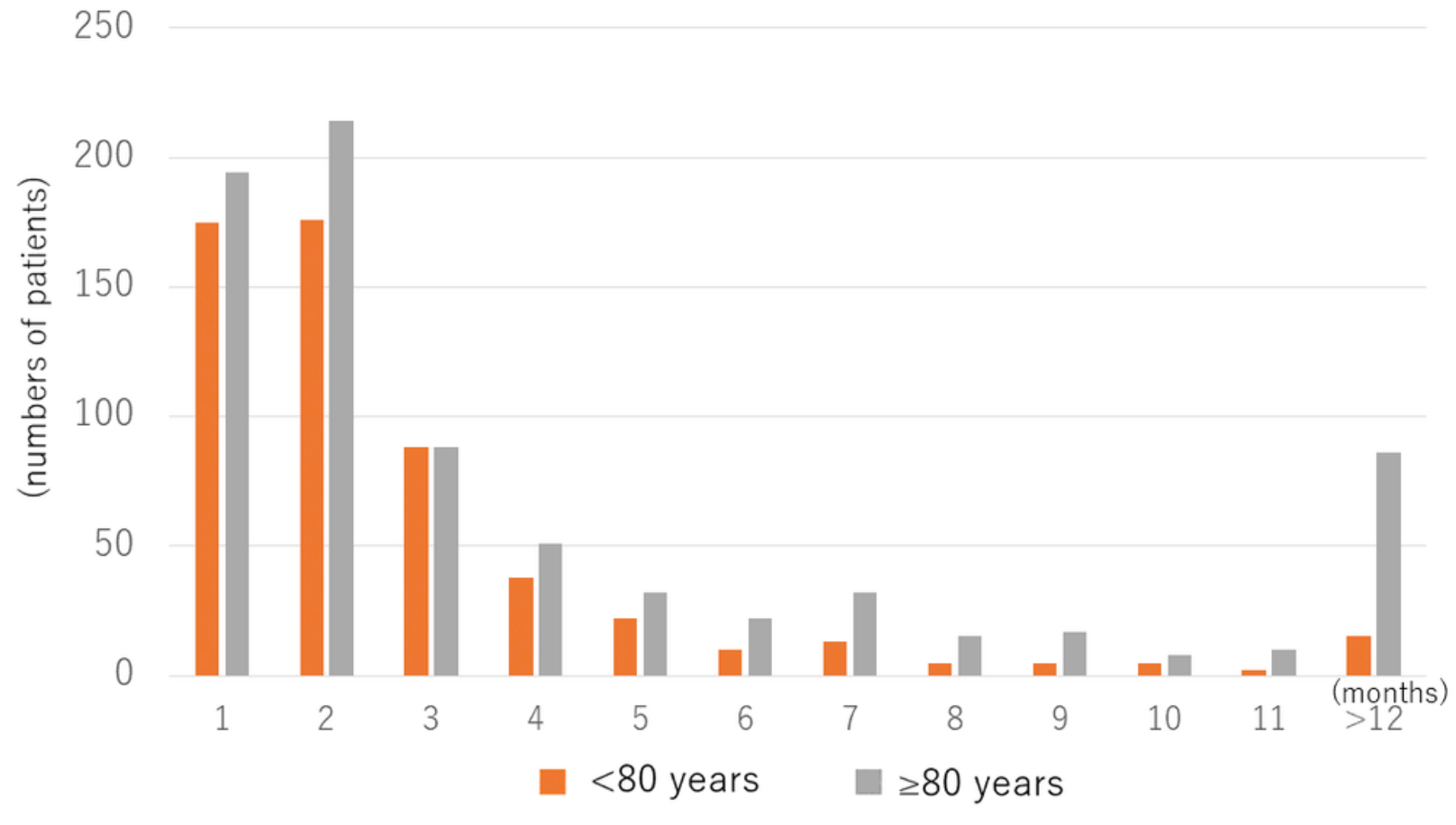

Figure 2

Survival time after the introduction of HEC. The average overall survival time at home was $3.9 \pm 4.4$ months. The average survival time at home was longer in the $\geq 80$-year group than that in the $<80$-year group (4.6 vs. 2.9 months, $p<0.001$ ). HEC, home end-of-life care. 